\title{
Can Wideband Tympanometry Be Used as a Screening Test for Superior Semicircular Canal Dehiscence?
}

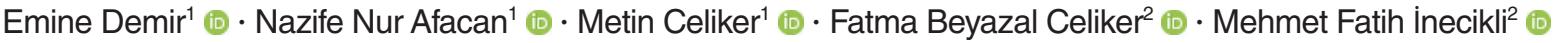 \\ Suat Terzi ${ }^{1}$ (1) $\cdot$ Engin Dursun ${ }^{1}$ (i)
}

Departments of ${ }^{1}$ Otorhinolaryngology and ${ }^{2}$ Radiology, Recep Tayyip Erdogan University Faculty of Medicine, Rize, Turkey

Objectives. We explored whether wideband tympanometry (WBT) could be used as a screening test for superior semicircular canal dehiscence (SSCD), and obtained new WBT data (given that the test is not yet in common clinical use) on patients with SSCD.

Methods. We compared the WBT data of patients clinically and radiologically diagnosed with SSCD in our hospital between 2013 and 2018 to those of healthy volunteers. We compared the resonance frequency (RF), maximum absorbance frequency (MAF), and maximum absorbance ratio (MAR). The $t$-test was used for statistical analysis with the significance level set to $P<0.05$. In addition, we used receiver operating characteristic analysis to derive cutoff values for SSCD diagnosis in terms of sensitivity and specificity.

Results. Seventeen patients (four with bilateral and 13 with unilateral disease; 17 ears) diagnosed with SSCD and 27 healthy volunteers (47 ears) were included. The mean RFs of the SSCD patients and healthy subjects were $548.7 \mathrm{~Hz}$ (range, 243 to $853 \mathrm{~Hz}$ ) and $935.1 \mathrm{~Hz}$ (range, 239 to 1,875 Hz), respectively $(P<0.001)$. The mean MARs of the SSCD patients and healthy subjects were $89.4 \%$ (range, $62 \%$ to $100 \%$ ) and $82.4 \%$ (range, $63 \%$ to $99 \%$ ), respectively $(P=0.005)$. The mean MAFs of the SSCD patients and healthy subjects were $1,706.3 \mathrm{~Hz}$ (range, 613 to 3,816 $\mathrm{Hz}$ ) and $2,668 \mathrm{~Hz}$ (range, 876 to $4,387 \mathrm{~Hz}$ ), respectively $(P<0.001)$. In terms of SSCD diagnosis, a MAR above $86 \%$ afforded $81 \%$ sensitivity and $77 \%$ specificity; an RF below $728 \mathrm{~Hz}, 86 \%$ sensitivity and $81 \%$ specificity; and an MAF below $1,835 \mathrm{~Hz}, 79 \%$ sensitivity and $67 \%$ specificity.

Conclusion. WBT may be a useful clinical screening test for SSCD. The RF and MAF were lower, and the MAR higher, in SSCD patients than in normal controls.

Keywords. Tympanometry; Semicircular Canal; Dehiscence; Resonance Frequency; Acoustic Impedance Test

\section{INTRODUCTION}

Superior semicircular canal dehiscence (SSCD) is an audiovestibular pathology first described in 1998 by Minor et al. [1]. The SSC develops a defect in the bony roof that forms a "third moving

- Received August 1, 2018

Revised September 20, 2018

Accepted October 1, 2018

- Corresponding author: Emine Demir

Department of Otorhinolaryngology, Recep Tayyip Erdogan University

Faculty of Medicine, Sehitler St., No. 74, Rize 53020, Turkey

Tel: +90-4642130491, Fax: +90-4642130364

E-mail: emine.demir@erdogan.edu.tr window" in the bony labyrinth. This allows the endolymph to move under the influence of loud noise or pressure, triggering vestibular symptoms such as dizziness, nystagmus, and oscillopsia [2] and cochlear findings such as conductive hearing loss, autophonia, bone conduction hyperacusis, tinnitus, and ear fullness [3]. However, as these symptoms are not specific to SSCD, they cannot be used alone for diagnosis. High-resolution computed tomography (HRCT) is useful, as are audiological tests such as tympanometry, acoustic reflex evaluation, and audiography. In addition, the cervical vestibular-evoked myogenic potential (cVEMP) test is employed for screening. However, the need for high-level patient compliance and various factors associated with standard-

Copyright (C) 2019 by Korean Society of Otorhinolaryngology-Head and Neck Surgery.

This is an open-access article distributed under the terms of the Creative Commons Attribution Non-Commercial License (http://creativecommons.org/licenses/by-nc/4.0)

which permits unrestricted non-commercial use, distribution, and reproduction in any medium, provided the original work is properly cited. 
ization limit the use of cVEMP for diagnostic purposes [4,5].

The tympanometer is a noninvasive immitansmetric instrument assessing sound transmission in the middle ear. The resistance or permeability of the middle ear to a sound at constant frequency $(226 \mathrm{~Hz})$ is assessed by changing the pressure in the external auditory canal [6]. The wideband tympanometer allows immitansmetric measurements over a wide frequency range (226 to $8,000 \mathrm{~Hz}$ ) by changing the pressure of both the ambient and external auditory canals. The wideband acoustic absorbance measured reflects sound energy absorbed by the middle ear, whereas the wideband acoustic reflectance is the reflected sound energy. These two measurements are inversely proportional and sum to unity. The wideband acoustic reflectance values are highest below $1,000 \mathrm{~Hz}$ and above $4,000 \mathrm{~Hz}$ [7]. Thus, the absorbance ratios are highest in these frequency ranges. The maximum absorbance frequency (MAF) of wideband tympanometry (WBT) lies in this range under normal conditions. Another parameter evaluated is the resonance frequency (RF), which is the frequency at which the mass and stiffness effects of the middle ear are equal. The middle ear transmits sound at the RF more readily than sounds at other frequencies [8]. WBT data are thus quite different from those obtained via tympanometry, affording extensive insight into the middle and inner ears, and facilitating identification of various pathologies. However, WBT is relatively new; few normative data are available $[9,10]$. WBT data from patients with various ear diseases/pathologies are scarce. The primary aim of this study was to explore whether WBT could serve as a simple, noninvasive screening test for SSCD. Our secondary aim was to derive WBT data on SSCD patients.

\section{MATERIALS AND METHODS}

\section{Participants}

Our local Ethics Committee approved this study (No. 2018/45). All participants provided written informed consent. We radiologically assessed and clinically diagnosed SSCD patients (the SSCD group) treated in the Otorhinolaryngology Department of Recep Tayyip Erdogan University Faculty of Medicine, Rize, Turkey between 2013 and 2018, as well as healthy volunteers (the normal group). The inclusion criteria for the normal group

\section{H I G H L I G H T S}

- Wideband tympanometry could be used as a noninvasive, inexpensive and easy screening test for superior semicircular canal dehiscence.

- Inner ear absorbance ratio increased in patient with superior semicircular canal dehiscence.

- Resonance frequency is obtained at lower frequencies in patient with superior semicircular canal dehiscence. were a normal otological examination; no otorhinolaryngological surgical history; and no cochleovestibular complaint such as hearing loss, tinnitus, or vertigo. The pure tone audiometry, tympanometry, and acoustic reflex test data were all normal. The inclusion criteria for the SSCD group were a radiological diagnosis of SSCD, a normal otological examination, no otorhinolaryngological surgical history, normal tympanometry, pure tone audiometry, and acoustic reflex test results, and a threshold reduction on the SSCD side on cVEMP testing.

\section{Radiological evaluation}

SSCD was radiologically diagnosed via HRCT, performed in our hospital at a slice thickness of $0.75 \mathrm{~mm}$ (128 slices) (SOMATOM; Siemens, Munich, Germany). The operating parameters were 120 $\mathrm{kV}, 220 \mathrm{~mA}$, and $186 \times 186$-pixel field-of-view. Alternatively, the slice thickness was $0.625 \mathrm{~mm}$ (256 slices) (Discovery CT750 HD; General Electric, Boston, MA, USA) with operating parameters of $140 \mathrm{kV}, 150 \mathrm{~mA}$, and $190 \times 186$-pixel field of view. Multiplanar reformatted images were obtained using a workstation running Syngo software (ver.VA20; Siemens Healthcare, Forchheim, Germany). SSCD was detected by vertical angling in the coronal plane that was perpendicular to the petrosal bone and parallel to the SSCD (the Pöschl plan); and parallel to the petrosal bone and perpendicular to the SSCD (the Stenvers plan). All radiological evaluations were performed by two radiologists (FBC, MFI) with experience in head-and-neck imaging, blinded to both the affected side and the clinical findings. Loss of integrity of the bony roof surrounding the SSC was considered to reflect dehiscence.

\section{Audiological assessment}

The cVEMP test was performed with the aid of an Eclipse VEMP device (Interacoustics, Assens, Denmark). The test featured a 500-Hz tone-burst stimulus. The initial stimulus was $95 \mathrm{~dB}$, which was lowered until a $10-\mathrm{dB}$ response was obtained. If no response was obtained, the threshold was determined via stepwise $(5 \mathrm{~dB})$ increases [11]. A cVEMP value $<80 \mathrm{dN} n H L$ was used to diagnose SSCD.

The tympanometer was employed in conjunction with an acoustic reflex tester (AT235H device, Interacoustics) operating at a frequency of $226 \mathrm{~Hz}$. Type A patients (using the Jerger calcification) were considered normal [12]. All tympanometry and acoustic reflex data were normal for all individuals in both groups. Pure tone audiometry tests were performed using an AC40 device (Interacoustics). Pure tone averages were obtained at $500,1,000,2,000$, and $4,000 \mathrm{~Hz}$. The air and bone pathway thresholds of all subjects were normal $(\leq 30 \mathrm{~dB})$. SSCD patients may exhibit conductive hearing loss on pure tone audiometry testing [13]. Bone conduction hyperacusis is another possible symptom of SSCD. The combined increase in bone conduction hyperacusis and the air conduction threshold creates an air-bone gap (ABG). Thus, we extended the start point for evaluation of 
bone conduction to $-20 \mathrm{~dB}$ nHL. In patients with SSCD, WBT test results may be affected by the $\mathrm{ABG}$ and bone conduction hyperacusis occurring at low frequencies. For this reason, patients with $\mathrm{ABGs}$, i.e., those exhibiting conductive hearing loss or hyperacusis, were excluded.

WBT was performed using the Titan device (Interacoustics). Measurements were made at 0 pressure (da Pa) using a $90 \pm 3 \mathrm{~dB}$ sound stimulus. We recorded the RF, maximum absorbance ratio (MAR), and MAF. OtoAccess software (ver. 1.2.1, Interacoustics) was used to analyze the data.

\section{Statistical analyses}

Statistical analyses were performed using IBM SPSS ver. 20.0 (IBM Corp., Armonk, NY, USA). The RF, MAR, and MAF values of the normal and SSCD groups were compared using the $t$-test. The statistical significance level was set to $P<0.05$. In addition, receiver operating characteristic (ROC) analyses were performed to derive cutoff values for all data in terms of SSCD diagnosis. We explored whether the data could be used for screening based on specificity and sensitivity.

\section{RESULTS}

In the normal group, we included 47 ears (right, 22; left, 25) of 27 subjects (14 females, 13 males; average age, 39.7 years; range, 20 to 64 years). Seventeen SSCD patients (four with bilateral disease) were included; we studied 21 ears (right, 9; left, 12) of seven females and 10 males with an average age of 39.6 years

Table 1. Demographic data in normal and SSCD groups

\begin{tabular}{lcc}
\hline Variable & Normal group & SSCD group \\
\hline Age $(\mathrm{yr})$ & $39.7 \pm 10.9(20-64)$ & $39.6 \pm 14.1(21-63)$ \\
Sex & & \\
$\quad$ Female & $14(51.8)$ & $7(41.1)$ \\
$\quad$ Male & $13(48.2)$ & $10(58.9)$ \\
Including/affected ear & & \\
$\quad$ Right & $22(46.8)$ & $9(42.8)$ \\
Left & $25(53.2)$ & $12(57.2)$ \\
\hline
\end{tabular}

Values are presented as mean \pm standard deviation (range) or number (\%). SSCD, superior semicircular canal dehiscence.

Table 2. Wideband tympanometry data in normal and SSCD groups

\begin{tabular}{lcc}
\hline Variable & Normal group & SSCD group \\
\hline Resonance frequency $(\mathrm{Hz})$ & $935.1 \pm 344.4$ & $548.7 \pm 182.9$ \\
& $(239-1,875)$ & $(243-853)$ \\
Maximum absorbance & $2,668 \pm 1,054.5$ & $1,706.3 \pm 862$ \\
frequency $(\mathrm{Hz})$ & $(876-4,387)$ & $(613-3,816)$ \\
Maximum absorbance & $82.4 \pm 8.6$ & $89.4 \pm 10.4$ \\
ratio $(\%)$ & $(63-99)$ & $(62-100)$ \\
\hline
\end{tabular}

Values are presented as mean \pm standard deviation (range). SSCD, superior semicircular canal dehiscence. (range, 21 to 63 years) (Table 1 ).

The reasons for polyclinic admission included voice-induced vertigo (the Tullio phenomenon, $n=5$ ), pressure-induced vertigo (Hennebert sign, $n=2)$, dizziness-like vertigo $(n=8$; accompanied

Table 3. Normal group data

\begin{tabular}{|c|c|c|c|c|c|c|}
\hline Subject & Age (yr) & Sex & Including ear & RF & MAR & MAF \\
\hline 1 & 49 & Male & L & 733 & 85 & 2,230 \\
\hline \multirow[t]{2}{*}{2} & 39 & Male & $\mathrm{R}$ & 839 & 83 & 3,890 \\
\hline & & & L & 839 & 82 & 3,894 \\
\hline \multirow[t]{2}{*}{3} & 33 & Female & $\mathrm{R}$ & 556 & 80 & 993 \\
\hline & & & $\mathrm{L}$ & 730 & 97 & 876 \\
\hline 4 & 49 & Male & $\mathrm{R}$ & 889 & 99 & 2,097 \\
\hline \multirow[t]{2}{*}{5} & 44 & Female & $\mathrm{R}$ & 1,243 & 83 & 2,910 \\
\hline & & & L & 1,106 & 85 & 2,866 \\
\hline 6 & 30 & Female & $\mathrm{L}$ & 981 & 97 & 2,310 \\
\hline \multirow[t]{2}{*}{7} & 33 & Female & $\mathrm{R}$ & 1,098 & 78 & 3,000 \\
\hline & & & L & 1,246 & 96 & 2,360 \\
\hline \multirow[t]{2}{*}{8} & 46 & Female & $\mathrm{R}$ & 839 & 82 & 3,698 \\
\hline & & & $\mathrm{L}$ & 839 & 84 & 3,987 \\
\hline \multirow[t]{2}{*}{9} & 26 & Male & $\mathrm{R}$ & 885 & 66 & 2,000 \\
\hline & & & L & 857 & 71 & 1,890 \\
\hline 10 & 46 & Male & $L$ & 846 & 95 & 2,670 \\
\hline \multirow[t]{2}{*}{11} & 28 & Male & $\mathrm{R}$ & 301 & 73 & 1,236 \\
\hline & & & $L$ & 926 & 80 & 2,360 \\
\hline \multirow[t]{2}{*}{12} & 42 & Male & $\mathrm{R}$ & 743 & 82 & 2,574 \\
\hline & & & $\mathrm{L}$ & 799 & 81 & 4,346 \\
\hline \multirow[t]{2}{*}{13} & 32 & Female & $\mathrm{R}$ & 1,875 & 84 & 3,990 \\
\hline & & & $\mathrm{L}$ & 1,108 & 84 & 3,716 \\
\hline \multirow[t]{2}{*}{14} & 48 & Female & $\mathrm{R}$ & 1,079 & 98 & 2,490 \\
\hline & & & $L$ & 1,127 & 83 & 2,498 \\
\hline \multirow[t]{2}{*}{15} & 31 & Female & $\mathrm{R}$ & 1,432 & 63 & 4,290 \\
\hline & & & $L$ & 1,256 & 97 & 3,127 \\
\hline \multirow[t]{2}{*}{16} & 64 & Male & $\mathrm{R}$ & 1,065 & 81 & 3,098 \\
\hline & & & $L$ & 239 & 69 & 1,099 \\
\hline 17 & 45 & Male & $\mathrm{R}$ & 999 & 92 & 3,203 \\
\hline \multirow[t]{2}{*}{18} & 60 & Male & $\mathrm{R}$ & 252 & 79 & 3,999 \\
\hline & & & $L$ & 859 & 76 & 4,387 \\
\hline \multirow[t]{2}{*}{19} & 20 & Female & $\mathrm{R}$ & 1,048 & 94 & 4,053 \\
\hline & & & L & 902 & 82 & 4,230 \\
\hline \multirow[t]{2}{*}{20} & 50 & Female & $\mathrm{R}$ & 732 & 78 & 1,102 \\
\hline & & & $L$ & 763 & 81 & 987 \\
\hline \multirow[t]{2}{*}{21} & 34 & Male & $\mathrm{R}$ & 788 & 80 & 2,306 \\
\hline & & & $L$ & 471 & 79 & 1,471 \\
\hline 22 & 24 & Female & L & 1,316 & 88 & 3,248 \\
\hline \multirow[t]{2}{*}{23} & 45 & Female & $\mathrm{R}$ & 1,240 & 78 & 2,109 \\
\hline & & & L & 960 & 86 & 1,514 \\
\hline 24 & 54 & Male & $\mathrm{L}$ & 593 & 77 & 1,987 \\
\hline \multirow[t]{2}{*}{25} & 31 & Female & $\mathrm{R}$ & 1,875 & 82 & 3,876 \\
\hline & & & $L$ & 1,108 & 84 & 2,310 \\
\hline \multirow[t]{2}{*}{26} & 44 & Female & $\mathrm{R}$ & 316 & 85 & 3,213 \\
\hline & & & $L$ & 1,316 & 72 & 1,618 \\
\hline \multirow[t]{2}{*}{27} & 35 & Male & $\mathrm{R}$ & 1,126 & 79 & 1,302 \\
\hline & & & L & 813 & 66 & 1,986 \\
\hline
\end{tabular}

RF, resonance frequency; MAR, maximum absorbance ratio; MAF, maximum absorbance frequency; $L$, left; $R$, right. 

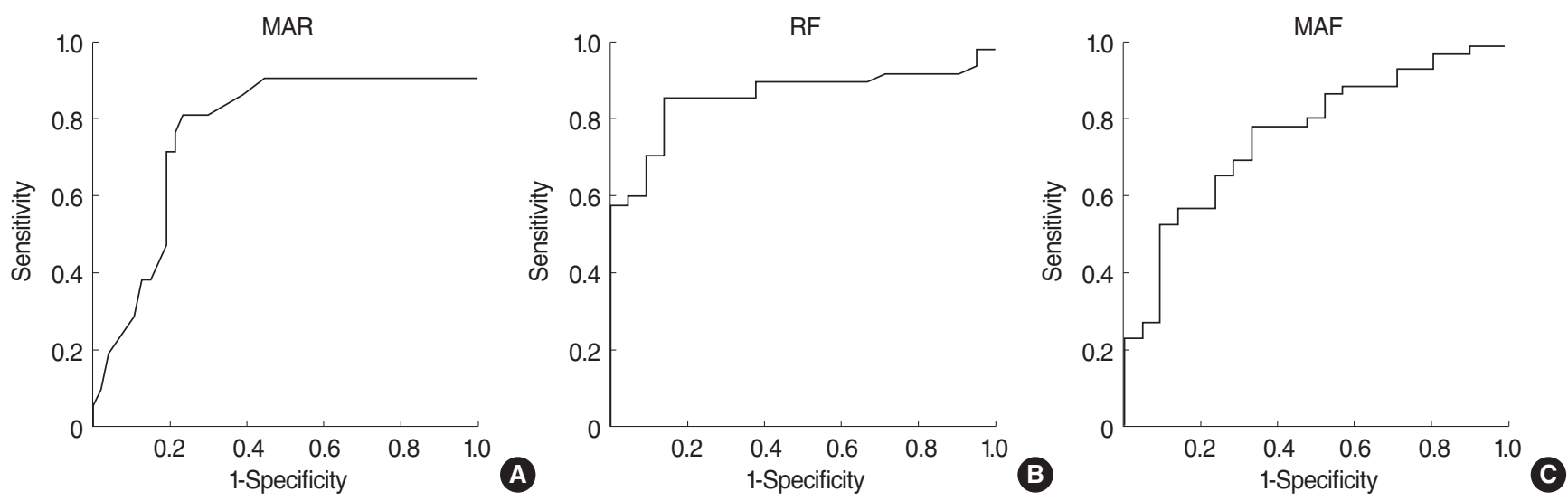

Fig. 1. Receiver operating characteristic curves showing that (A) a maximum absorbance ratio (MAR) over $86 \%$ afforded $81 \%$ sensitivity and $77 \%$ specificity; (B) an resonance frequency (RF) below $728 \mathrm{~Hz}$ afforded $86 \%$ sensitivity and $81 \%$ specificity; and (C) an maximum absorbance frequency (MAF) below $1,835 \mathrm{~Hz}$ afforded $79 \%$ sensitivity and $67 \%$ specificity.

Table 4. SSCD group data

\begin{tabular}{cclccrr}
\hline Subject & Age $(\mathrm{yr})$ & Sex & Affected ear & RF & MAR & MAF \\
\hline 1 & 42 & Female & $\mathrm{L}$ & 534 & 89 & 757 \\
2 & 24 & Female & $\mathrm{R}$ & 316 & 98 & 1,280 \\
3 & 38 & Male & $\mathrm{R}$ & 684 & 87 & 1,530 \\
& & & $\mathrm{~L}$ & 727 & 100 & 1,234 \\
4 & 55 & Male & $\mathrm{L}$ & 243 & 94 & 2,437 \\
5 & 41 & Male & $\mathrm{L}$ & 721 & 97 & 1,088 \\
6 & 63 & Male & $\mathrm{R}$ & 693 & 96 & 3,816 \\
7 & 58 & Female & $\mathrm{R}$ & 330 & 90 & 2,331 \\
& & & $\mathrm{~L}$ & 494 & 91 & 1,780 \\
8 & 19 & Male & $\mathrm{L}$ & 471 & 92 & 1,664 \\
9 & 21 & Male & $\mathrm{R}$ & 487 & 62 & 981 \\
& & & $\mathrm{~L}$ & 455 & 62 & 613 \\
10 & 33 & M & $\mathrm{L}$ & 343 & 97 & 1,775 \\
11 & 46 & Female & $\mathrm{R}$ & 531 & 99 & 1,013 \\
12 & 42 & Female & $\mathrm{R}$ & 480 & 98 & 2,210 \\
13 & 47 & Male & $\mathrm{L}$ & 810 & 89 & 931 \\
14 & 21 & Male & $\mathrm{R}$ & 844 & 83 & 1,216 \\
& & & $\mathrm{~L}$ & 853 & 84 & 1,160 \\
15 & 48 & Female & $\mathrm{L}$ & 538 & 86 & 3,610 \\
16 & 55 & Male & $\mathrm{R}$ & 640 & 89 & 2,061 \\
17 & 42 & Female & $\mathrm{R}$ & 330 & 96 & 2,346 \\
\hline
\end{tabular}

SSCD, superior semicircular canal dehiscence; RF, resonance frequency; MAR, maximum absorbance ratio; MAF, maximum absorbance frequency; $L$, left; R, right.

by tinnitus in two cases), and acute-onset vertigo $(n=2)$. Benign paroxysmal positional vertigo was ruled out in all patients, especially those with acute-onset vertigo. All otological pathologies that may cause vertigo were also ruled out based on history-taking and physical examination. Detailed neurological examinations were performed and biochemical tests conducted. Patients with pathologies that might trigger vertigo were excluded.

The mean RF was $935.1 \mathrm{~Hz}$ (range, 239 to $1,875 \mathrm{~Hz}$ ) in the normal and $548.7 \mathrm{~Hz}$ (range, 243 to $853 \mathrm{~Hz}$ ) in the SSCD group; the difference was significant $(P<0.001)$. The mean MAR was
$82.4 \%$ (range, $63 \%$ to $99 \%$ ) in the normal group and $89.4 \%$ (range, $62 \%$ to $100 \%$ ) in the SSCD group; the difference was significant $(P=0.005)$. The mean MAF was $2,668 \mathrm{~Hz}$ (range, 876 to $4,387 \mathrm{~Hz}$ ) in the normal group and $1,706.3 \mathrm{~Hz}$ (range, 613 to $3,816 \mathrm{~Hz}$ ) in the SSCD group; the difference was significant $(P<0.001)$ (Table 2).

All three datasets were subjected to ROC analysis. In terms of SSCD diagnosis, a MAR above $86 \%$ (area under the curve [AUC], $0.77 \pm 0.07 ; 95 \%$ confidence interval [CI], 0.63 to 0.90 ) afforded $81 \%$ sensitivity and $77 \%$ specificity; an RF below $728 \mathrm{~Hz}$ (AUC, $0.86 \pm 0.05 ; 95 \% \mathrm{CI}, 0.76$ to 0.95$) 86 \%$ sensitivity and $81 \%$ specificity, and an MAF below 1,835 Hz (AUC, 0.77 $\pm 0.06 ; 95 \%$ CI, 0.65 to 0.89 ) $79 \%$ sensitivity and $67 \%$ specificity (Fig. 1). As the AUCs were all $0.5-1$, and the safety intervals were very high, all three parameters can be used for diagnostic screening. Data on all participants are detailed in Tables 3 and 4.

\section{DISCUSSION}

HRCT can confirm a diagnosis of SSCD [14]. However, the radiological prevalence of SSCD is very variable, more so than on histopathological testing. In addition, most patients with radiological diagnoses are asymptomatic. Clinical findings are evident in only about one of every three patients with dehiscence, perhaps because SSC bone thinning to less than $0.1 \mathrm{~mm}$ is required before dehiscence is recognized. Thus, diagnosis requires both clinical and radiological assessments $[15,16]$. HRCT should be performed after suspect patients first undergo clinical tests; screening tests with high diagnostic utility are needed.

cVEMP tests performed at low frequencies $(250$ and $500 \mathrm{~Hz}$ ) can be used for clinical screening [11]. However, the cVEMP test has several limitations, including a lack of consensus in terms of the SSCD diagnostic threshold, lack of standardization, the fact that patients with cervical disease find it difficult or im- 
possible to perform the test, individual differences in muscle activity and mass, difficulties in calculating these values, and decreases in VEMP responses with age $[5,17,18]$. We found no literature on the cVEMP threshold for SSCD diagnosis. However, in general, the response thresholds of our patients were below $80 \mathrm{~dB}[11,15,19]$. Thus, we set the cVEMP limit to $80 \mathrm{~dB}$.

When HRCT is used to diagnose SSCD, the margin of error may be high because of the absence of clinical correlations. Furthermore, if used as a screening test, HRCT is relatively costly and carries the risks associated with ionizing radiation. The cVEMP test has several limitations. Therefore, screening tests that are inexpensive, reliable, and simple are required.

A missed SSCD diagnosis may delay appropriate treatment, both of SSCD per se and of other underlying diseases (e.g., Meniere disease, otosclerosis, and/or eustachian tube dysfunction) [13]. However, it should not be forgotten that an incorrect SSCD diagnosis may trigger unnecessary exploratory tympanotomies and unsuccessful stapedectomies [20]. Therefore, screening tests should be used to confirm the diagnosis, thus addressing underlying diseases in patients suspected as having SSCD and radiological bone defects.

Although some normative WBT data are available, variations by age, sex, ear side, medical device used, and ethnicity are considerable $[7,9,21]$. Thus, we designed our study by reference to earlier work done in our clinic and derived normative WBT data for the Turkish population [10]. The present study was conducted in the same ethnic group, using the same device. Our results were not affected by ear side or sex. In terms of age group, only the RF of subjects aged 0-1 months differed from those of subjects aged 2 months to 20 years; the MARs and MAFs did not differ [10]. Subjects aged below 20 years differed from older subjects in these parameters, but all subjects aged over 20 years were similar. Therefore, there was no need to group patients by age.

WBT is used to evaluate sound transmission from the middle to the inner ear, and sound reflection from the middle ear over a wide frequency range (principally 1,000-4,000 Hz). Middle ear conductance is optimal in this band, as is inner ear sensitivity $[7,22]$. In other words, the RF, MAF, and MAR values yielded by WBT reflect the condition of both the middle and inner ear. WBT yields information on both middle and inner ear diseases. Thus, we evaluated WBT data from patients radiologically and clinically diagnosed with SSCD.

We found that the RF was significantly lower in SSCD patients than in normal subjects. Sato et al. [22] performed multifrequency tympanometry and obtained RF scans of patients with large vestibular aqueducts (LVAs). The RFs of LVA patients were lower than those of the normal population. Taking our work into consideration, we suggest that the symptoms of both LVA and SSCD are attributable to the third windows created by both diseases. We also found that the MAFs of SSCD patients were significantly lower than those of healthy subjects. In SSCD patients, the inner ear responds better to low frequencies, per- haps because the vibrational effects of such frequencies expand the inner ear fluid (which is particularly susceptible to vibration), in line with the fact that the cVEMP test threshold was low. In addition, SSCD patients had higher MARs than normal individuals. The RFs and MAFs were both lower in SSCD patients than healthy individuals; the MARs increased in patients with SSCD. We suggest that these findings reflect the enhanced inner ear sensitivity of SSCD. We thus suggest thatWBT may be a good alternative to the cVEMP test for SSCD screening. WBT is better than the cVEMP test in terms of procedural ease, reduced need for patient compliance, and lower dependency on personal factors such as age, weight, and muscle mass.

We also obtained WBT data on SSCD patients. However, at present it is not possible to compare our results to those obtained from patients with other middle and inner ear pathologies. WBT is relatively new, such that additional normative data are required. However, RFs can be expected to be higher, and inner ear absorbances to decrease, in those with pathologies increasing ear hardness, such as otosclerosis and tympanosclerosis. Voice conduction to the inner ear becomes more difficult if the ossicular chain is fractured. Thus, in terms of the middle ear space, the data would be expected to be the opposite to those of SSCD. WBT data in patients with various middle and inner ear pathologies should be compared in future.

Our principal aim in this study was to assess whether WBT could be used as a screening test for SSCD. We found significant differences between the WBT data of SSCD patients and healthy individuals, suggesting that WBT might be a useful clinical screening test. ROC analysis showed that a MAR over $86 \%$, and an RF and MAF below 728 and 1,835 Hz, respectively, served as appropriate cut-off values for SSCD diagnosis.

Our study had certain limitations. A definitive diagnosis of SSCD is made during surgery, via a mid-fossa approach, when a bone defect is found in the SSC. We informed all SSCD-suspect patients of this, in terms of both diagnosis and treatment. However, the patients refused surgery because of the possible risks. The principal limitation of our study is that it lacked surgical diagnoses. However, all radiological evaluations were performed in a double-blinded manner by two radiologists experienced in head-and-neck thin-section HRCT, and we also included patients with cVEMP values below $80 \mathrm{~dB}$; we thus suggest that our study is of high clinical quality. Moreover, the fact that inner ear sensitivity was elevated on WBT testing supports this suggestion. A second limitation is that the number of patients was low, although our findings were statistically significant. Standardized SSCD diagnostic criteria must be derived using larger patient series, in multi-center studies if necessary. Third, dehiscence diameters should be categorized and associated with WBT data in larger patient series. Does the dehiscence diameter affect the WBT results, and if so, how?

Our results suggest that WBT can serve as a noninvasive, inexpensive, and simple screen for SSCD. The MAR is higher, and the 
RF and MAF lower, in SSCD patients than in healthy individuals. The data support the idea that inner ear sensitivity is increased in SSCD patients; the inner ear is less resistant to sound.

\section{CONFLICT OF INTEREST}

No potential conflict of interest relevant to this article was reported.

\section{ORCID}

Emine Demir

https://orcid.org/0000-0003-4087-432X

Nazife Nur Afacan

https://orcid.org/0000-0002-5106-2549

Metin Celiker

https://orcid.org/0000-0002-9833-402X

Fatma Beyazal Celiker https://orcid.org/0000-0002-5420-9825

Mehmet Fatih İnecikli https://orcid.org/0000-0002-9796-8223

Suat Terzi

https://orcid.org/0000-0002-1131-3649

Engin Dursun

https://orcid.org/0000-0002-2070-8677

\section{AUTHOR CONTRIBUTIONS}

Conceptualization: ED. Data curation: NNA, FBC, MFI. Formal analysis: FBC, MFI. Methodology: NNA, ST. Project administration: MC. Visualization: ST.Writing - original draft, review \& editing: ED.

\section{REFERENCES}

1. Minor LB, Solomon D, Zinreich JS, Zee DS. Sound- and/or pressureinduced vertigo due to bone dehiscence of the superior semicircular canal.Arch Otolaryngol Head Neck Surg. 1998 Mar;124(3):249-58.

2. Mau C, Kamal N, Badeti S, Reddy R, Ying YM, Jyung RW, et al. Superior semicircular canal dehiscence: diagnosis and management. J Clin Neurosci. 2018 Feb;48:58-65.

3. Minor LB. Clinical manifestations of superior semicircular canal dehiscence. Laryngoscope. 2005 Oct;115(10):1717-27.

4. Zhou G, Gopen Q, Poe DS. Clinical and diagnostic characterization of canal dehiscence syndrome: a great otologic mimicker. Otol Neurotol. 2007 Oct;28(7):920-6.

5. Rauch SD. Vestibular evoked myogenic potentials. Curr Opin Otolaryngol Head Neck Surg. 2006 Oct;14(5):299-304.
6. Rosowski JJ, Nakajima HH, Hamade MA, Mahfoud L, Merchant GR, Halpin CF, et al. Ear-canal reflectance, umbo velocity, and tympanometry in normal-hearing adults. Ear Hear. 2012 Jan-Feb;33(1): 19-34.

7. Feeney MP, Grant IL, Marryott LP. Wideband energy reflectance measurements in adults with middle-ear disorders. J Speech Lang Hear Res. 2003 Aug;46(4):901-11.

8. Margolis RH, Van Camp KJ, Wilson RH, Creten WL. Multifrequency tympanometry in normal ears. Audiology. 1985;24(1):44-53.

9. Shahnaz N, Davies D. Standard and multifrequency tympanometric norms for Caucasian and Chinese young adults. Ear Hear. 2006 Feb;27(1):75-90.

10. Ozgur A, Mujdeci B, Terzi S, Ozergin Coskun Z, Yigit E, Dursun E. Wideband tympanometry normative data for different age groups in Turkish population. J IntAdv Otol. 2016 Apr;12(1):82-6.

11. Roditi RE, Eppsteiner RW, Sauter TB, Lee DJ. Cervical vestibular evoked myogenic potentials (cVEMPs) in patients with superior canal dehiscence syndrome (SCDS). Otolaryngol Head Neck Surg. 2009 Jul;141(1):24-8.

12. Jerger J. Clinical experience with impedance audiometry. Arch Otolaryngol. 1970 Oct;92(4):311-24.

13. Merchant GR, Roosli C, Niesten ME, Hamade MA, Lee DJ, McKinnon ML, et al. Power reflectance as a screening tool for the diagnosis of superior semicircular canal dehiscence. Otol Neurotol. 2015 Jan;36(1):172-7.

14. Klopp-Dutote N, Kolski C, Biet A, Strunski V, Page C. A radiologic and anatomic study of the superior semicircular canal. Eur Ann Otorhinolaryngol Head Neck Dis. 2016 Apr;133(2):91-4.

15. Saliba I, Maniakas A, Benamira LZ, Nehme J, Benoit M, MontreuilJacques V. Superior canal dehiscence syndrome: clinical manifestations and radiologic correlations. Eur Arch Otorhinolaryngol. 2014 Nov;271(11):2905-14.

16. Cloutier JF, Belair M, Saliba I. Superior semicircular canal dehiscence: positive predictive value of high-resolution CT scanning. Eur Arch Otorhinolaryngol. 2008 Dec;265(12):1455-60.

17. Welgampola MS, Colebatch JG. Characteristics and clinical applications of vestibular-evoked myogenic potentials. Neurology. 2005 May;64(10):1682-8.

18. Kim KW, Jung JY, Lee JH, Suh MW. Capacity of rectified vestibular evoked myogenic potential in correcting asymmetric muscle contraction power. Clin Exp Otorhinolaryngol. 2013 Dec;6(4):209-13.

19. Brantberg K, Bergenius J, Tribukait A. Vestibular-evoked myogenic potentials in patients with dehiscence of the superior semicircular canal.Acta Otolaryngol. 1999;119(6):633-40.

20. Castellucci A, Brandolini C, Piras G, Modugno GC. Tympanometric findings in superior semicircular canal dehiscence syndrome. Acta Otorhinolaryngol Ital. 2013 Apr;33(2):112-20.

21. Polat Z, Bas B, Hayır D, Bulut E, Atas A. Wideband tympanometry normative data for turkish young adult population. J Int Adv Otol. 2015 Aug;11(2):157-62.

22. Sato E, Nakashima T, Lilly DJ, Fausti SA, Ueda H, Misawa H, et al. Tympanometric findings in patients with enlarged vestibular aqueducts. Laryngoscope. 2002 Sep;112(9):1642-6. 